\title{
Ordered Iron Oxide Nanotube Arrays of Controlled Geometry and Tunable Magnetism by Atomic Layer Deposition
}

\author{
Julien Bachmann, ${ }^{*}, \dagger$ Jing Jing, ${ }^{\dagger}$ Mato Knez, ${ }^{\dagger}$ Sven Barth, ${ }^{\ddagger}$ Hao Shen, ${ }^{\ddagger}$ Sanjay Mathur, ${ }^{\ddagger}$ \\ Ulrich Gösele, ${ }^{\dagger}$ and Kornelius Nielsch ${ }^{*} \dagger$ \\ Max Planck Institute of Microstructure Physics, Am Weinberg 2, 06120 Halle, Germany, and Leibniz Institute of \\ New Materials, CVD Division, Im Stadtwald, Geb. 43A, D-66041 Saarbruecken, Germany
}

Received April 18, 2007; E-mail: bachmann@mpi-halle.de; knielsch@mpi-halle.de

The interest in arrays of pseudo-one-dimensional ferromagnetic nanoobjects stems from their potential application to high-density data storage. ${ }^{1}$ This communication reports on the fabrication of iron oxide nanotubes by atomic layer deposition (ALD) and the opportunities thus afforded in the magnetic realm.

Among the different geometric types of objects, tubes offer an additional degree of freedom in their design as compared to wires, in that not only the length and diameter can be varied but also the thickness. Changes in thickness are expected to strongly affect the mechanism of magnetization reversal and thereby the overall magnetic response-in particular, the remnant magnetization. ${ }^{2}$ The physics of ferromagnetic nanotubes, however, have remained illdefined to date for lack of systems amenable to systematic experimental variations in the geometric parameters and study of the corresponding variations in the magnetic behavior. ${ }^{3}$ Common experimental limitations include difficult synthesis of magnetic tubes of sub-100 nm diameter, ${ }^{2 \mathrm{~b}}$ granularity of the tube structure, ${ }^{3,4}$ and inhomogeneities in thickness and/or diameter. ${ }^{5}$ In contrast to this, atomic layer deposition (ALD) of magnetic materials can be applied to ordered porous substrates to yield arrays of smooth tubes with a geometry that is $(a)$ tightly controlled and $(b)$ widely tunable. ${ }^{6}$ Our focus on iron oxides results from their unique position among the magnetic materials in terms of abundant availability and biocompatibility.

Water and the homoleptic dinuclear iron(III) tert-butoxide complex, $\mathrm{Fe}_{2}\left(\mathrm{O}^{t} \mathrm{Bu}\right)_{6},{ }^{7}$ were used for ALD of $\mathrm{Fe}_{2} \mathrm{O}_{3}$. When the $\mathrm{Fe}_{2}\left(\mathrm{O}^{t} \mathrm{Bu}\right)_{6}$ precursor was heated to $100{ }^{\circ} \mathrm{C}$, a temperature window was found between 130 and $170{ }^{\circ} \mathrm{C}$ in which the solid deposits in amounts proportional to the number of reaction cycles. At lower temperatures, deposition does not occur as judged from the absence of color. The onset of $\mathrm{Fe}_{2}\left(\mathrm{O}^{t} \mathrm{Bu}\right)_{6}$ thermal decomposition sets the upper limit of ALD. ${ }^{7}$ When the process is carried out with a selfordered porous anodic alumina membrane ${ }^{8}$ as the substrate, the internal walls are covered conformally with a smooth layer of $\mathrm{Fe}_{2} \mathrm{O}_{3}$, yielding arrays of tubes of aspect ratios up to 100, the growth rate being $0.26( \pm 0.04) \AA$ cycle $^{-1}$, as displayed in Figures 1 and S9. The results are unaffected by preliminary and/or subsequent ALD of $\mathrm{ZrO}_{2}$ or $\mathrm{TiO}_{2}$, which can be used to facilitate the preparation of samples for electron microscopy (see Supporting Information). X-ray photoelectron spectroscopy (XPS) confirms the identity of the deposited material to be $\mathrm{Fe}_{2} \mathrm{O}_{3}$, albeit with a high carbon content (Figure S6). The amount of $\mathrm{C}$ decreases with depth, which could be due to residual superficial tert-butoxide ligands unhydrolyzed by their first exposure to water. Selected-area electron diffraction (SAED) indicates that the tubes are nanocrystalline, with only very short-range order. Relative to the ALD processes reported to date for iron metal or its oxides, based either on an iron(II) amidinate

$\dagger$ Max Planck Institute

\$ Leibniz Institute.

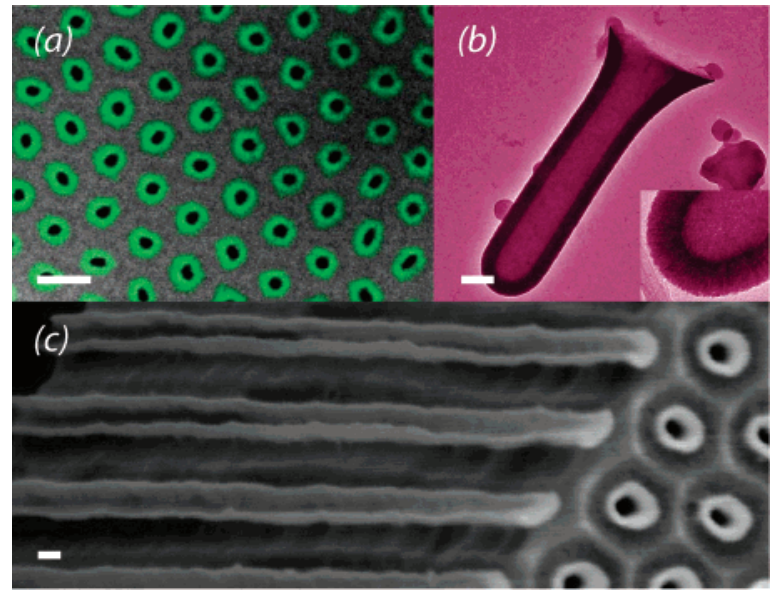

Figure 1. Electron micrographs (scanning, SEM; transmission, TEM) of the iron oxide tubes. Scale bars: $100 \mathrm{~nm}$. (a) SEM of an array of narrow tubes $\left(11( \pm 4) \mathrm{nm} \mathrm{Fe}_{2} \mathrm{O}_{3}\right.$, green circles) embedded in the alumina template; contrast enhanced by colorization (original micrograph provided in Figure S5). (b) TEM of a single thick and short tube $\left(42( \pm 4) \mathrm{nm} \mathrm{Fe} \mathrm{O}_{4}\right)$ isolated by dissolution of the template; the inset zooms in on the very smooth wall. (c) SEM of an array of thick $\mathrm{ZrO}_{2} / \mathrm{Fe}_{2} \mathrm{O}_{3} / \mathrm{ZrO}_{2}$ tubes $(12( \pm 2) / 26( \pm 4) /$ $12( \pm 2) \mathrm{nm})$ embedded in the template: edge view at a crack, with tubes broken in their length and emerging on the top side of the membrane.

and $\mathrm{H}_{2}$ or on an iron(III) acetylacetonate and $\mathrm{O}_{2}$ or $\mathrm{O}_{3},{ }^{9}$ the novel method simultaneously improves the growth rate, the smoothness, and the aspect ratios accessed vastly. Its low deposition temperature also makes it attractive for nanostructuring applications based on selected biotemplates. ${ }^{10}$

Reduction of the $\mathrm{Fe}_{2} \mathrm{O}_{3}$ nanotubes in the $\mathrm{Al}_{2} \mathrm{O}_{3}$ matrix by $5 \%$ $\mathrm{H}_{2} / 95 \%$ Ar at $400{ }^{\circ} \mathrm{C}$ converts $\mathrm{Fe}_{2} \mathrm{O}_{3}$ to $\mathrm{Fe}_{3} \mathrm{O}_{4},{ }^{11}$ as substantiated by XPS (Figure S6). The transformation is accompanied by a color change from golden or coppery brown to black, commensurate with the decrease in band gap. The reduced tubes are air-sensitive and were kept under inert atmosphere by depositing a macroscopic layer of polystyrene onto the membranes. This protection allows for their convenient handling in air without appreciable degradation over a period of days to weeks.

The $\mathrm{Fe}_{3} \mathrm{O}_{4}$ tubes behave as hard ferromagnets at $300 \mathrm{~K}$, as shown by SQUID data (Figure 2). At lower temperatures, the magnetic hystereses widen, an approximate doubling in coercive field being usually observed between 300 and $5 \mathrm{~K}$ (Figure S2). Temperaturedependent magnetization data (Figure S4) do not show any abrupt change indicative of a crystallographic phase transition (Verwey transition), ${ }^{12}$ an observation consistent with a glassy structural state.

Coercive fields $\left(\mathrm{H}_{\mathrm{c}}{ }^{\prime \prime}\right)$ as high as $76.5( \pm 1.5) \mathrm{mT}(765( \pm 15)$ Oe $)$ can be obtained at room temperature for the $\mathrm{Fe}_{3} \mathrm{O}_{4}$ tube arrays (in parallel applied field), a value which compares favorably to the largest reported to date for $\mathrm{Fe}_{3} \mathrm{O}_{4}$ zero- and one-dimensional 


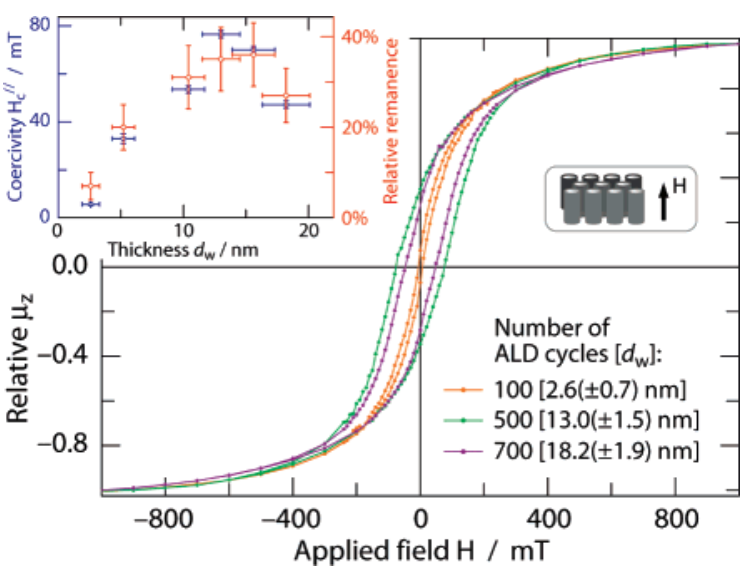

Figure 2. Magnetic hystereses of $\mathrm{Fe}_{3} \mathrm{O}_{4}$ tube arrays $(50( \pm 5) \mathrm{nm}$ outer diameter, 105 $( \pm 10) \mathrm{nm}$ center-to-center distance, various wall thicknesses $\left.d_{\mathrm{w}}\right)$ in porous alumina at $300 \mathrm{~K}$, in a magnetic field $\mathrm{H}$ applied along the tubes $(z)$; a paramagnetic contribution due to the template was subtracted, and the $z$ moment $\mu_{z}$ was normalized. Inset: properties (blue, coercivity $\mathrm{H}_{\mathrm{c}}{ }_{\mathrm{c}}$; red, remanence relative to $\left.1 \mathrm{~T}\right)$ for $2.6( \pm 0.7) \leq d_{\mathrm{w}} \leq 18.2( \pm 1.9) \mathrm{nm}$.

nanoobjects. ${ }^{2 b, 5,13}$ More importantly, our synthetic approach offers the unique opportunity to vary the geometry of the tubes at will and in a tightly controlled fashion. Figure 2 focuses on $\mathrm{Fe}_{3} \mathrm{O}_{4}$ tubes of $50 \mathrm{~nm}$ outer diameter and shows the dramatic evolution of their magnetic properties when the wall thickness $d_{\mathrm{w}}$ is varied. Soft ferromagnetism is observed in the limit of very thin tubes, with vanishing remnant magnetization and coercive field. Increasing the thickness of the $\mathrm{Fe}_{3} \mathrm{O}_{4}$ tubes yields a monotonic improvement of their magnetic properties up to an optimum situated near $d_{\mathrm{w}}=13$ nm. Further thickness increases are accompanied by receding remanence and coercivity. While our semiquantitative micromagnetic $(\text { Oommf })^{14}$ simulations of a single tube isolated in vacuum allow one to expect the initial increase in $\mathrm{H}_{\mathrm{c}}{ }^{\prime \prime}$ with $d_{\mathrm{w}}$, they do not reproduce the trend observed for $13 \mathrm{~nm}<d_{\mathrm{w}}<20 \mathrm{~nm}$ (Figure S7). Consequently, we ascribe the latter to the interaction of each tube with the stray fields produced by the array-an effective antiferromagnetic coupling between neighboring tubes, which reduces $\mathrm{H}_{\mathrm{c}}$ " as previously demonstrated for the case of nickel nanowires. ${ }^{1 \mathrm{~d}, 15}$ Indeed, the stray field produced by the ensembles of nanotubes at magnetic saturation are significant, on the order of $45 \mathrm{mT}$ for $d_{\mathrm{w}}=7 \mathrm{~nm}$ and $85 \mathrm{mT}$ for $d_{\mathrm{w}}=15 \mathrm{~nm}$ (see Supporting Information). The experimental magnetic anisotropy of the tube arrays further corroborates our interpretation, in that applying the external field $\mathrm{H}$ perpendicular to the long axis $(z)$ of the tubes instead of parallel to it results in large $\mathrm{H}_{\mathrm{c}}{ }^{\perp}$ values (on the order of 60-70 mT, virtually independent of $d_{\mathrm{w}}$, Figure S3). This observation, which contrasts the situation of isolated tubes (presenting the easy magnetization axis on $z$ ), is a recognized hallmark of strong interactions between magnetic neighbors. ${ }^{16}$

The results of this communication highlight the importance of a well-controlled chemical synthesis in the context of solid-state physics. ${ }^{17}$ For the preparation of well-defined, tunable, ordered nanostructures, ALD has proven to be the ideal method. It has enabled us to observe a strong size dependence in the magnetism of $\mathrm{Fe}_{3} \mathrm{O}_{4}$ nanotubes and identify an optimal thickness. A more thorough understanding of the phenomenon unveiled here will be required for engineering future high-density data storage systems. Our findings warrant detailed analytical investigation of the ALD reaction (particularly with regard to the $\mathrm{C}$ content of the deposited film), further experimental study on the magnetism of nanotube arrays and its dependence on geometry, as well as theoretical modeling of the magnetization reversal in such structures.
Acknowledgment. We thank L. Zhang for experimental assistance. This work was supported by the Bundesministerium für Bildung und Forschung: 03N8701 (MPI), 03X5512 (INM). S.M. thanks the Saarland State and the Leibniz Association for financial support. J.B. acknowledges the A. von Humboldt Foundation for a postdoctoral fellowship (3-SCZ/1122413 STP).

Supporting Information Available: Experimental procedures, hystereses at $5 \mathrm{~K}$ and in perpendicular applied field, temperaturedependent magnetization, original SEM micrograph for Figure 1a, XPS data, micromagnetic simulations, stray field calculation, saturation of the ALD reaction, TEM micrograph of tubes in aspect ratio $\geq 100$. This material is available free of charge via the Internet at http://pubs.acs.org.

\section{References}

(1) (a) Whitney, T. M.; Jiang, J. S.; Searson, P. C.; Chien, C. L. Science 1993, 261, 1316-1319. (b) Prinz, G. A. Science 1998, 282, 1660-1663. (c) Thurn-Albrecht, T.; Schotter, J.; Kastle, C. A.; Emley, N.; Shibauchi, T.; Krusin-Elbaum, L.; Guarini, K.; Black, C. T.; Tuominen, M. T.; Russell, T. P. Science 2000, 290, 2126-2129. (d) Nielsch, K.; Wehrspohn, R. B.; Barthel, J.; Kirschner, J.; Gösele, U.; Fischer, S. F.; Kronmüller, H. Appl. Phys. Lett. 2001, 79, 1360-1362.

(2) (a) Escrig, J.; Landeros, P.; Altbir, D.; Vogel, E. E.; Vargas, P. J. Magn Magn. Mater. 2007, 308, 233-237. (b) Sui, Y. C.; Skomski, R.; Sorge, K. D.; Sellmyer, D. J. Appl. Phys. Lett. 2004, 84, 1525-2527.

(3) A notable exception: Nielsch, K.; Castaño, F. J.; Matthias, S.; Lee, W.; Ross, C. A. Adv. Eng. Mater. 2005, 5, 217-221.

(4) Sui, Y. C.; Zhou, J.; Li, X. Z.; Skomski, R.; Sellmyer, D. J. J. Appl. Phys. 2004, 95, 6741-6743.

(5) Yang, J. B.; Xu, H.; You, S. X.; Zhou, X. D.; Wang, C. S.; Yelon, W. B.; James, W. J. J. Appl. Phys. 2006, 99, 08Q507.

(6) (a) Puurunen, R. L. Appl. Phys. Rev. 2005, 97, 121301. (b) Knez, M.; Nielsch, K.; Niinistö, L. Adv. Mater. 2007, submitted. (c) Daub, M.; Knez, M.; Gösele, U.; Nielsch, K. J. Appl. Phys. 2007, 101, 09J111.

(7) (a) Mathur, S.; Veith, M.; Sivakov.; V.; Shen, H.; Huch, V.; Hartmann, U.; Gao, H. B. Chem. Vap. Deposition 2002, 8, 277-283. (b) Spandl, J.; Kusserow, M.; Bruedgam, I. Z. Anorg. Allg. Chem. 2003, 629, 968-974 (c) Mathur, S.; Sivakov, V.; Shen, H.; Barth, S.; Cavelius, C.; Nilsson, A.: Kuhn, P. Thin Solid Films 2006, 502, 88-93.

(8) (a) Masuda, H.; Fukuda, K. Science 1995, 266, 1466-1468. (b) Nielsch, K.; Choi, J.; Schwirn, K.; Wehrspohn, R. B.; Gösele, U. Nano Lett. 2002, $2,677-680$

(9) (a) Lim, B. S.; Rahtu, A.; Gordon, R. G. Nat. Mater. 2003, 2, 749-754. (b) Lie, M.; Fjellvåg, H.; Kjekshus, A. Thin Solid Films 2005, 488, 7481. (c) Nilsen, O.; Lie, M.; Foss, S.; Fjellvåg, H.; Kjekshus, A. Appl. Surf. Sci. 2004, 227, 40-47. (d) de Ridder, M.; van de Ven, P. C.; van Welzenis, R. G.; Brongersma, H. H.; Helfensteyn, S.; Creemers, C.; Van Der Voort, P.; Baltes, M.; Mathieu, M.; Vansant, E. F. J. Phys. Chem. B 2002, 106, 13146-13153.

(10) Knez, M.; Kadri, A.; Wege, C.; Gösele, U.; Jeske, H.; Nielsch, K. Nano Lett. 2006, 6, 1172-1177.

(11) (a) Regazzoni, A. E.; Urrutia, G. A.; Blesa, M. A.; Maroto, A. J. G. J Inorg. Nucl. Chem. 1981, 43, 1489-1493. (b) Jiao, F.; Jumas, J. C. Womes, M.; Chadwick, A. V.; Harrison, A.; Bruce, P. G. J. Am. Chem. Soc. 2006, 128, 12905-12909.

(12) Verwey, E. J. W. Nature 1939, 44, 327-328.

(13) (a) Zhang, L.-Y.; Xue, D.-S.; Xu, X.-F.; Gui, A.-B. J. Magn. Magn. Mater. 2005, 294, 10-15. (b) Kazakova, O.; Erts, D.; Crowley, T. A.; Kulkarni, J. S.: Holmes, J. D. J. Magn. Magn. Mater. 2006, 286, 171-176. (c) Abid, M.; Abid, J.-P.; Jannin, S.; Serrano-Guisan, S.; Palaci, I.; Ansermet, J.-P. J. Phys.: Condens. Matter 2006, 18, 6085-6093. (d) Latham, A H.; Wilson, M. J.; Schiffer, P.; Williams, M. E. J. Am. Chem. Soc. 2006, 128, 12632-12633. (e) Wan, J.; Chen, X.; Wang, Z.; Yang, X.; Qian, Y J. Cryst. Growth 2005, 276, 571-576. (f) Goya, G. F.; Berquó, T. S . Fonseca, F. C. J. Appl. Phys. 2003, 94, 3520-3528.

(14) Donahue, M. J.; Porter, D. G. Interagency Report NISTIR 6376: NIST, Gaithersburg, MD, 1999; http://math.nist.gov/oommf

(15) (a) Hertel, R. J. Appl. Phys. 2001, 90, 5752-5758. (b) Hwang, M. Abraham, M. C.; Savas, T. A.; Smith, H. I.; Ram, R. J.; Ross, C. A. J. Appl. Phys. 2000, 87, 5108-5110. (c) Jang, H.-J.; Eames, P.; Dahlberg, E. D.; Farhoud, M.; Ross, C. A. Appl. Phys. Lett. 2005, 86, 023102/1023102/3. (d) Sorop, T. G.; Untiedt, C.; Luis, F.; Kroll, M.; Rasa, M.; de Jongh, L. J. Phys. Rev. B 2003, 67, 014402/1-014402/8. (e) Martin, J. I.; Nogues, J.; Liu, Kai; Vicent, J. L.; Schuller, Ivan K. J. Magn. Magn. Mater. 2003, 256, 449-501.

(16) (a) Nielsch, K.; Castaño, F. J.; Ross, C. A.; Krishnan, R. J. Appl. Phys. 2005, 98, 034318. (b) Sorop, T. G.; Nielsch, K.; Göring, P.; Kroll, M.; Blau, W.; Wehrspohn, R. B.; Gösele, U.; de Jongh, L. J. J. Magn. Magn. Mater. 2004, 272, 1656-1657. (c) Bao, J. C.; Xu, Z.; Hong, H. M.; Ma, X.; Lu, Z. H. Scr. Mater. 2004, 50, 19-23.

(17) This theme has been emphasized previously: Grohol, D.; Nocera, D. G. J. Am. Chem. Soc. 2002, 124, 2640-2646.

JA072465W 